On the Relationship Between Time Management and Time Estimation

\author{
J.A.Francis-Smythe \\ * University College Worcester \\ Henwick Grove, \\ Worcester WR2 6AJ \\ Tel: 01905-855242; e-mail : j.francis-smythe@worc.ac.uk
}

Ivan.T.Robertson

SHL/UMIST Centre for Research in Work and Organisational Psychology

** Manchester School of Management

Sackville St,

UMIST,

Manchester M60 1QD

Tel: 0161-200-3443 


\section{On the Relationship Between Time Management and Time Estimation}

The study explores the relationship between people's selfreport of the use of time management practices and estimates of task duration. The hypothesis is that those who are good time managers will be good at estimating how long a future task will take (expected), how long a previously executed task has taken (retrospective) and how long a task is taking while in process (prospective). In the expected setting results indicate that those who perceive themselves as good time managers are most accurate at estimating the duration of a future task, of those who do not perceive themselves as good time managers some grossly overestimate and many underestimate to quite a considerable extent. The latter finding thus provides support for the 'planning fallacy' (Kahneman \& Tversky,1979). In the prospective setting results indicate those who perceive themselves as good time managers tend to underestimate time passing. It is suggested that this is a motivational strategy designed to enhance a sense of control over time. Findings are discussed in relation to existing theories of time estimation.

Keywords: time management, duration estimation, 
For some years now time management has been portrayed as having benefits for both individuals and organisations, typically positive time management practices are associated with self-evaluations of academic performance (Macan, Shahani, Dipboye \& Phillips,1990), objective grade point average (Britton \& Tesser, 1991), job satisfaction (Landy, Rastegary, Thayer \& Colvin, 1991), self-perceived organisational performance (Lim,1993) and actual car sales performance (Barling, Kelloway \& Cheung,1996).

Whilst these studies have focused on the effects of time management, rather less focus has been given to the construct itself. What exactly is time management and how should we measure it? Is it a set of learned behaviours or the manifestation of a combination of specific personality traits? Is it related in some way to basic personality dimensions such as extraversion and neuroticism ? Is the ability to manage time related to accuracy in estimating time? A more detailed knowledge about the construct itself is required in order to provide more detailed insights into its effects on individuals and organisations.

Attempts to answer these sorts of questions have begun to be made recently by the development of time management measures (e.g. Bond \& Feather,1988; Francis-Smythe \& Robertson, under review; Macan, Shahani, Dipboye and Phillips,1990; Usunier \& Valette-Florence,1994); an investigation of the dispositional nature of time management (Shahani, Weiner \& Streit,1993); and the relationship between time management and time estimation (Burt \& Kemp, 1994). 
This paper is concerned with exploring further the nature of the construct of time management by extending the work of Burt and Kemp (1994) on the relationship between time management and time estimation.

Time management, according to Lakein (1973), involves determining needs, setting goals to achieve the needs, prioritising the tasks required and matching tasks to time and resources through planning, scheduling and making lists. Whilst these activities address an essential first stage in time management, that of effective planning, there is also an additional and perhaps even more crucial second stage - that of keeping to the schedule. How then might there be a relationship between the activities in these two stages and time estimation?

For the first stage, 'Matching tasks to time and resources through planning and scheduling' requires the ability to predict reasonably accurately how long it will take to perform the task i.e. to be able to estimate, in advance, the duration of a task. Evidence for people being able to predict duration times accurately in advance, appears to date, to be inconsistent. Buehler, Griffin and Ross (1994) suggest people consistently underestimate project duration times, whereas Burt and Kemp (1994) showed subjects generally overestimated. It is important to note however, that these studies addressed different time-scales. Buehler et al.(1994) focused on days/weeks and Burt and Kemp (1994) minutes.

Buehler et al.(1994) based their work on the earlier work of Kahneman and Tversky (1979), who proposed the existence of a 'planning fallacy' (the 
tendency to hold a confident belief that one's own project will proceed as planned, even while knowing that the vast majority of similar projects have run late). Buehler et al. (1994) explored the reasons why people underestimate completion times, showing across a series of five studies that fewer than one half of the participants finished their tasks in the amount of time they originally predicted. They showed that people mostly use 'singular information' to estimate duration ('singular information' focuses specifically on constructing narratives and scenarios for completing the task rather than 'distributional information' which considers past experience with similar tasks, Kahneman \& Tversky,1979). Buehler et al. (1994) suggest possible reasons for this as: (a) the forward nature of prediction actually prevents reflection on the past; (b) a general inability to apply a similar experience (even if retrieved) to the present one and (c) causal attributions are made about previous instances which reduce their pertinence to the present case (a tendency to explain failure to meet a deadline as due to an external,unstable and specific factor related to that situation).

Interestingly, however, Burt and Kemp (1994) propose that we do use distributional information in predicting task times, albeit not from specific instances but from knowledge about the durations of categories of events (e.g. estimating how long dinner this evening will take in a specific restaurant is based on a general schema of eating out in restaurants). They suggest that future durations are generated constructively and that memory plays an important role. More recent work (Burt \& Popple, 1996) has also explored how specific memories of event duration are subject to reconstructive 
processes after the event (for example recall through the use of a question including the word 'walk' versus 'run' alters the event duration).

Stage two involves keeping to the schedule set. Assuming a realistic schedule has been set, then keeping to this schedule is likely to require an ability to monitor time as it passes (hereafter called prospective). For example, imagine having scheduled a meeting, with a full agenda, to take place between 2 and $4 \mathrm{pm}$ and for another activity to begin at 4pm. It is necessary, between 2 and $4 \mathrm{pm}$, to monitor time as it passes to ensure that the agenda is covered in the time allocated. Admittedly, this may well be through continual reference to an external indicator of time, such as a clock, but in instances where a clock is not visible, an ability to estimate time passing is essential. How do people go about this? It seems plausible to suggest that one way is by reflecting, at designated points (e.g. on completion of an agenda item), how much time has just past. Typically, knowing we are one hour into the meeting, might have been deduced by keeping a running total of time spent on each item. In this way monitoring time in-passing might simply reflect an ability accurately to estimate retrospective durations. If this were the case then the ability to estimate time spent on a task just completed (hereafter called retrospective) might also be an important predictor of ability to keep to a schedule.

As already noted, good time management requires the ability to both plan a schedule and keep to a schedule. It is proposed that this will involve an ability to predict in advance how long a task will take (expected duration estimate), to estimate time in-passing (prosective duration estimate), and 
retrospectively how long the task (or sub-components of the task) have taken (retrospective duration estimate).

All three time estimation paradigms exist in the literature (see Burt \& Kemp,1994, Block,1989 for examples). Four methods of estimation within each of the three paradigms (expected, prospective, retrospective) have traditionally been used: verbal/graphical estimation, production, reproduction and comparison. To date expected duration studies have utilised only the verbal estimation method, where participants estimate in minutes and seconds how long they think a task will take. Prospective studies have tended to utilise time production, where participants are told to carry out an activity for a specified amount of time, and retrospective studies either verbal/graphical estimation or the comparison method. In the comparison method the interval to be estimated is compared to a previous interval.

Different paradigms have tended to generate different explanatory models, typically, memory models (e.g. storage size-Ornstein,1969; contextual change models -Block,1978,1989) to explain retrospective estimates and attentional models (e.g.Thomas \& Weaver,1975; for review see Marmaras et al.,1995) to explain prospective estimates. Memory models suggest that the remembered duration of an event interval is directly and positively correlated with the information stored in memory during the interval. The more complex the material or the more changes experienced the longer the perceived duration. In contrast, the attentional approach sugggests that processing resources are shared between a temporal processor (timer), which counts and stores subjective temporal units (STUs), and other non-temporal processing 
activities. Diverting attention away from the timer to the task in-hand causes fewer STUs to be created and stored during a given interval and as a result subjective duration decreases with increase in the attentional demands of the non-temporal task. It should be noted that the majority of this early work has been based on durations of seconds, whereas the time-scales involved in activities related to time management are at the level of tens of minutes through to months and years. This may mean that the theoretical models of time estimation postulated and tested to date may not be relevant in this context. The work reported here manipulates attentional demand in a prospective task (watching a video, low demand; completing a crossword puzzle, high demand). If the attentional model applies then the crossword duration estimates should be shorter than the video estimates. However, it may be that for prospective duration, estimates in minutes interest level in the task becomes as important a determinant of estimation duration as attentional demand. As long ago as 1890, William James said, "In general, a time filled with varied and interesting experiences seems short in passing but long as we look back. On the other hand, a tract of time empty of experiences seems long in passing, but in retrospect short". This and our general experience of 'time flies when you are having fun' suggests individual interest level in the task might be an important variable in duration estimation of activities spanning minutes.Accordingly, the study reported below monitored self-reported interest levels in the prospective tasks.

Table 1 lists some of the recent time estimation studies categorising them in terms of theoretical model, paradigm, method and level of interval duration. 
Insert Table 1 about here

Although no work has yet been reported exploring the relationship between actual time management behaviours and expected duration estimations, Burt and Kemp (1994) have studied self-report time management behaviours as measured with the Time Structure Questionnaire (TSQ, Bond \& Feather, 1988). Students were first required to estimate the duration of ten activities (e.g. going for a specified walk, completing a form, sorting a pack of cards and so on) (Expected). They were then asked to complete the activities under timed conditions and to estimate how long they thought the activities had actually taken (Retrospective). The results showed a statistically significant positive correlation between expected and retrospective estimates leading the authors to conclude that such estimates are generated constructively from existing knowledge structures. Other researchers (e.g. Pedri \& Hesketh, 1993) suggest memory of time cues decay much faster than memory of significant events. Whilst this might suggest a problem for the maintenance of temporal information in knowledge structures it takes no account of individual differences. Given that rate of decay is affected by frequency of recall it follows that the more frequently time cues are recalled, the less they will decay. On this basis, good time managers may maintain time cues in memory through their regular utilisation, in the estimation of task duration. The hypothesis, based on this and the results of Burt and Kemp (1994) is that good time managers should be good at estimating the expected duration of a task.

Burt and Kemp (1994) tested this hypothesis with the TSQ (Bond \& Feather, 1994). Interestingly, and contrary to the hypothesis proposed, they showed 
that participants who felt that they were capable of managing their time were, in fact, quite poor at estimating how long it would take to perform a range of activities.

It should be noted that, although Burt and Kemp interpret high scores on the TSQ as showing capability to manage time, only one scale within the questionnaire, Structured Routine and Planning (Routine) was designed to measure aspects of time management behaviour. The present study explored this further by relating duration estimates to both the TSQ and a more specific four factor time management scale called the Time Management Behaviour Scale (TMBS, Macan, Shahani, Dipboye \& Philips, 1990). Three of the four factors in the TMBS relate specifically to time management behaviours: (1) Setting Goals and Priorities (Goal-setting - the setting of goals the person wants or needs to accomplish and prioritizing of the various tasks to achieve these goals); (2) Mechanics, Planning and Scheduling (Planning - the behaviours typically associated with managing time, such as making lists and planning); (3) Perceived Control of Time (Control - the extent to which one believes one can affect how time is spent). Both the TSQ and TMBS were considered appropriate for this study as their conceptual focus is at the level of daily tasks and, in addition, Mudrack (1997, p. 223) claims that these are "among the most promising of this new crop of time-oriented scales".

Burt and Kemp (1994) only tested links between estimates of the expected duration of tasks and self-report time management behaviours. Given the rationale presented earlier good time management should also involve being able to estimate accurately how long one has spent on a task once completed 
(retrospective) and on a task in-progress (prospective). This study therefore extends the work of Burt and Kemp (1994) by exploring relationships between expected, retrospective and prospective estimates and self-report time management behaviours.

A distinction needs to be drawn between duration estimates (the actual time in seconds that is estimated) and accuracy of estimates (the extent to which a person's estimate concurs with the actual duration). Burt and Kemp (1994) calculated proportional error scores for each subject as an indication of the inaccuracy (or error) of their duration estimates using a formula: (estimated duration - actual duration)/actual duration. For example, the expected error of a participant who estimates that a spell-checking task will take 600 seconds when it actually takes 300 will be $(600-300) / 300=+1$. The positive sign indicates the participant has overestimated, a negative sign indicates underestimation. The closer the error score to zero the more accurate the estimation. The average of participants' error scores ignoring the sign (thus according equal weight to over and underestimators) gives the mean accuracy of estimation for all participants on that task. High error indicates low accuracy. Given that there may be different relationships between self-report time management behaviours and time estimation ability for those who under and those who overestimate, direction of error was also considered in the study described below.

\section{Method}

\section{Experimental Design}


In the expected and retrospective paradigms verbal estimation was used, to replicate the work of Burt and Kemp (1994). In the prospective paradigm, the production method was used. This choice was made after a small pilot study was carried out with 10 subjects, using both the production and reproduction method. The production method was preferred for the main study because: (a) it gave the most accurate duration estimates in the pilot; (b) it could be most easily related to tasks in the workplace and (c) according to Block (1989), it shows the most inter-participant variability. Only one retrospective estimate can be made (thereafter participants are aware that they will be required to estimate time and all estimates become prospective), with this in mind the retrospective measure was conducted before the prospective measures. Subjects were told at the outset that the experiment was concerned with time management. Whilst this should have no effect on expected and prospective estimates it may affect retrospective estimates if subjects know in advance they will be required to estimate how long a task has taken (based on attention models of time estimation). However, in this study subjects were first asked to estimate expected duration and then asked to complete the task and generate an actual task duration time by means of a covered stop-watch which they controlled. Subjects were thus led to believe the experiment was concerned with how well predictions accorded with actual completion times and should therefore have had no inclination that a retrospective estimate would also later be required.

Two participants were randomly allocated to each of the 24 sequences of prospective tasks $(2$ videos and 2 puzzles $=4$ tasks $=4 \times 3 \times 2=24$ different sequences of the four tasks); thus 48 participants completed each of the four 
prospective tasks. The same 48 participants also completed each of the selfreport measures. The order of completion of the self-report measures was counter-balanced.

\section{$\underline{\text { Participants }}$}

Forty-eight people participated (17 men and 31 women; 52\% - 18-25 years, 11\%-26-35, 24\%-36-45, 10\%-46-55,2\%-56-65). Each particpant either studied or worked at the same higher education establishment. $70 \%$ were students, 21\% lecturers, 2\% technical staff and 6\% clerical staff. Approximately 90\% were educated to degree level.

\section{$\underline{\text { Apparatus }}$}

Three rooms without clocks were used and where practical (i.e. for the proofreading and puzzle tasks, see below) participants' chairs were separated by partitions. Participants were each given a stop-watch with the watch face covered by masking tape. The masking tape was peeled away from the watch face by the experimenter as and when necessary and time readings were taken directly from the stop-watch.

\section{$\underline{\text { Expected duration task }}$}

Participants were shown a single page of text (Times Roman, 14 pt, singlespaced) and asked to estimate how long they thought it would take, in seconds, to spell-check 3 pages of text similar to the one supplied. Given that at least $98 \%$ participants worked routinely with text this was chosen as a familiar task. Participants were asked to carry out the task of reading three pages of text and were timed whilst carrying out the task. 


\section{$\underline{\text { Retrospective tasks }}$}

Participants were asked to estimate retrospectively how long they thought it had taken them to complete the spell-check task in seconds.

\section{$\underline{\text { Prospective tasks }}$}

In each of the prospective conditions participants were asked to watch a video tape of a film or attempt a crossword puzzle. Prospective estimates in seconds were taken by asking participants to stop their covered watches when they thought ten minutes had passed, each watch was then read by the experimenter.

The tasks of watching a video tape and doing a crossword puzzle were chosen because they could be carried out for ten minutes (a typical task time in a work environment), had no obvious time cues, and would be sufficiently engaging to minimise the use of counting strategies. The two video tapes ( $A$ Few Good Men and Four Weddings and a Funeral) were chosen by asking ten students to rank order five Top Ten video films. A small pilot study was carried out to select the puzzles. Six crossword puzzles identified by a puzzle enthusiast as being of equivalent difficulty were given to five students to complete. The two crosswords showing the nearest to 80\% completion after 20 minutes were chosen.

\section{$\underline{\text { Self-report measures }}$}


Participants were first asked to complete a biographical data form requesting name, age group, occupation and sex.

Time Management Behaviour Scale (TMBS).

This 46 item five-point scale was designed to measure the extent to which time management behaviours are used, with high total scores indicating more frequent use (Macan et al., 1990). The whole scale has a coefficient alpha $(\alpha)$ of 0.68 and comprises four factors three of which are used in this study: Setting Goals and Priorities (Goal-setting $-\alpha=0.83$ ) (example item: I block out time in my daily schedule for regularly scheduled events); Mechanics Planning and Scheduling (Planning $\alpha=0.62$ ) (example item: I write notes to remind myself of what I need to do) and Perceived Control of Time (Control $\alpha=0.69$ ) (example item: I find myself socialising too much at work).

\section{Time Structure Questionnaire (TSQ)}

This 26 item, five factor scale was designed to measure the degree to which individuals perceive their use of time as structured and purposive (Bond \& Feather, 1988; Feather \& Bond, 1983). The whole scale comprises five factors only one of which is used here: Structured Routine (and planning) (example item: Do you have a daily routine which you follow?). The total TSQ score has an inter-item reliability of 0.90 .

\section{$\underline{\text { Interest. }}$}

Participants were asked to rate each puzzle and video tape for level of interest on a single 1-5 scale (1=very boring, 5=very interesting) immediately after completing the task. 


\section{Procedure}

Participants were asked to remove watches as they entered the room and then given a numbered stop-watch. Instruction in the use of the stopwatch was given. Participants were asked to wear the stop-watch around the neck and to keep their finger positioned over the stop button throughout the experimental periods. They were told that they would be completing five activities in three different rooms: (1) spell-check in Room A; (2) video one in Room B; (3) video two in Room C; (4) two puzzles in Room A and (5) several questionnaire measures in Room A. Details of each task were given just prior to the task being conducted. All participants first went to Room A and completed the biographical form followed by the expected duration estimate of the spell-check task. They were then asked to start their stop-watches and carry out the spell-check, stopping their watches as soon as they had finished. Researchers then noted the stop-watch readings and re-set the watches. All participants then completed the retrospective estimate of the spell-check task, before being given individual instructions indicating the order in which they should complete each of the four prospective tasks in Rooms A, B and C.

For the prospective tasks, participants were asked to start their stop-watch when indicated by the experimenter and then either 'sit back and enjoy the video' or 'do the crossword' until they felt ten minutes had passed, when they should stop their stop-watch. After an interval of between 16 and 20 minutes (the interval was varied so as not to be used as a cue) the experimenter stopped the experiment, read and reset the watches.An interest rating was 
made after each task. All participants then returned to Room A and completed the self-report measures.

Analysis and Results

Table 2 shows the mean duration estimates for each of the experimental tasks. Given the reported intra-participant variability in prospective duration estimates (Block, 1978), it was decided to take the average of two task estimations for each of the prospective duration estimates, i.e. video (mean) $=$ mean of the two video estimates, puzzle $($ mean $)=$ mean of the two puzzle estimates (see Table 2).

Insert Table 2 about here

Analyses of variance (ANOVA) were used to examine both task and order effects in each of the 4 prospective tasks (Video one, Video two, Puzzle one, Puzzle two). There were no statistically significant order effects but there was a task effect $(\mathrm{F}=7.9, \mathrm{p}<0.001, \mathrm{dF}=3,108)$ with puzzle estimates being significantly longer than video estimates. There was no statistically significant difference between the two video task estimates, nor between the two puzzle tasks. There was a statistically significant difference between the two mean task estimates $(\mathrm{F}=23.9, \mathrm{p}<0.001, \mathrm{dF}=1,46)$ with mean puzzle estimates being longer than mean video estimates.

Participants' interest levels in puzzles one and two were correlated $(\mathrm{r}=+0.76$, $\mathrm{p}<0.0001)$. Accuracy of crossword completion $(\mathrm{r}=+0.79, \mathrm{p}<0.0001)$ was also 
correlated across the two puzzles, indicating relatively consistent interest and performance levels across the puzzles. Interest levels were not consistent across the video tapes. There was no statistically significant relationship between interest level and prospective estimation duration in the video tape tasks, but there was for each of the puzzle tasks. Using analyses of variance, the study shows that people who thought the puzzles were very interesting estimated time as passing much more quickly than those who thought them very boring (Puzzle one $\mathrm{F}=2.67, \mathrm{dF}=4,42, \mathrm{p}<0.04$ ); Puzzle two, $\mathrm{F}=3.15, \mathrm{dF}=3,43, \mathrm{p}<0.03)$.

Analysis of the spell-check task data showed frequency distributions of the expected and retrospective duration estimates to be positively skewed, whilst the distribution of the actual and prospective durations were symmetrical. The skewness of the expected, in part due to occasional grossly overestimated durations, mirrors the findings of Burt and Kemp (1994). Table 3 shows the medians and inter-quartile deviations for the expected, actual and retrospective durations in this study and a similar task in the Burt and Kemp (1994) study.

Insert Table 3 about here

In the present study the median values of all three tasks are reasonably similar; in the Burt and Kemp (1994) study the actual and retrospective were similar but the expected was approximately 50\% larger. There appeared to be 
many gross overestimations of expected duration in the Burt and Kemp (1994) study.

Table 4 shows the means and standard deviations of the proportional error estimates both signed and non-signed. Non-signed error estimates are used simply to represent degree of accuracy, irrespective of direction (i.e. over or underestimation). In order to explore whether over and underestimators differed in accuracy, subjects were split into 3 groups (overestimators, accurates and underestimators) for each of the paradigms i.e. the same subject may be an overestimator in the expected paradigm but an underestimator in the retrospective. Groups were constructed so as to achieve as balanced a representation as possible of number of participants across groups whilst trying to place positive errors in the overestimators, negative errors in the underestimators and those nearest zero error in the accurates (see Table 5).

Insert Table 4 about here Insert Table 5 about here

For non-signed errors the prospective puzzle estimates were the most accurate, showing least variability, whereas the expected estimate was least accurate and showed most variability. Looking at signed errors, underestimation occurred to a similar extent in the expected, retrospective and video prospective conditions, much less in puzzle prospective and 
overestimation occured to the greatest extent in the expected followed by the retrospective paradigm.

Table 6 shows correlations of non-signed proportional error scores with each of the self-report measures. High error signifies low accuracy.

Insert Table 6 about here

In the expected paradigm there are statistically significant negative relationships between error and both the extent to which people perceive that they have control of their time (Control), and the extent to which people report engaging in time management behaviours . Correlations of error with Routine, Goal-setting, Planning and Total Time Management are not statistically significant but they are in the hypothesised direction. High perceived control of time therefore suggests greater accuracy in estimation of expected duration. Additional analyses were carried out by separating the participants into three groups : under-estimators; accurates and overestimators for each of the expected, prospective and retrospective tasks. Analyses of variance were computed to see if there were statistically significant differences in self-report variable scores (Routine, Goal-setting, Planning,Control, TotalTM) between the three groups on each of the tasks. Means for each analysis are shown in Table 7. In the expected task, the only statistically significant difference was for Control $(\mathrm{F}=5.52, \mathrm{dF}=2,39, \mathrm{p}<0.01)$ but each of the analyses revealed means in the hypothesised direction (i.e. accurates were higher on the self-report TM variable than either over or 
under-estimators who perceive themselves to be equally poor at controlling their time).

Insert Table 7 about here

As Table 6 shows the results from the puzzle prospective paradigm are in contrast to the expected paradigm. Four out of five of the correlations show statistically significant positive relationships with non-signed errors: Routine; Goal-setting; Planning and Total Time Management . These results suggests that those who perceive themselves to have a structured routine, set goals, plan and report the use of time management behaviours are likely to be poor estimators of time-in-passing. Looking more closely and examining under and overestimators separately, it can be seen with the prospective puzzle task there was a trend for underestimators to have the highest self-reported time management behaviours. Only the Planning sub-scale showed a statistically significant difference $(\mathrm{F}=3.5, \mathrm{dF}=2,40, \mathrm{p}<0.05)$, underestimators scored significantly higher than either accurates or overestimators.

As the results in Tables 6 and 7 show there were no statistically significant relationships between any of the self-report time measures and retrospective duration estimates.

\section{Discussion}

This part of the paper will focus first on discussing the findings relating to the accuracy of each of the duration estimation tasks and secondly, the findings relating to the hypothesised relationships between time management and time 
estimation. In both cases comparisons will be made across tasks and with the earlier work of Burt and Kemp (1994).

\section{Estimation accuracy}

Considering all participants together, the results of this study suggest that people are most accurate at estimating time in-passing and least accurate at estimating the duration of a future task. The expected and retrospective estimates showed most variation between participants. It is worth noting that this variation may be due to the fact that these are both verbally estimated, where rounding to the nearest minute may have taken place (even though participants were asked to estimate in seconds). The signed error results demonstrate that, in the expected task, accuracy is both poorest and shows greatest variation between participants suggesting, as with the Burt and Kemp (1994), study that a few people greatly overestimate. In contrast, while underestimation in the expected and retrospective paradigms is still relatively high there is far less variation, many people do it! In the expected paradigm particularly, a number of people underestimate by quite a large extent. This finding supports the 'planning fallacy' proposed by Kahneman and Tversky (1979). Burt and Kemp (1994) suggest that the inaccuracy shown in their experimental findings reflects a general tendency to overestimate, but did allude to the fact that this was skewed by a number of gross overestimations. It may be that an examination of underestimators, accurates and overestimators in their study might also provide evidence of the planning fallacy, and that the occurence of a few gross overestimations is hiding the planning fallacy phenomenon. 
Burt and Kemp (1994) explain this perceived tendency to overestimate as a safe estimation strategy, whereby unused time can be used to begin the next activity earlier. In the Burt and Kemp (1994) study participants were aware that once they had completed one task they would be free to start the next. In the current study this was not the case; all participants moved en-bloc from task to task, under the control of the experimenter, and hence unused time was not free to be used in the same way. The suggestion made here then, is that the purpose of the estimation may determine the strategy used, and that this, in turn, affects the accuracy of the duration estimates. The strategy used may be dependent on individual differences in motivation. For example, when estimating the expected duration of a future task, in order to facilitate planning and scheduling one may be motivated simply by successful completion of the task on time. In this case one would use a strategy to maximise accuracy. Alternatively, one may be more motivated by successful completion of the task early in order to then begin the next task early. This would give an enhanced sense of control over time. In this instance, an individual would be motivated to use the safe estimation strategy. If the purpose was to estimate time retrospectively, or time-in-passing, in order to keep to a schedule, then one would simply be motivated to be as accurate as possible. It is suggested that, in the current experiment, participants were motivated, in all conditions, to estimate duration as accurately as possible; whereas in the Burt and Kemp (1994) study they may well have been more motivated to use the safe estimation strategy.

Alternatively, it must be acknowledged that the different results found between the two studies may also reflect differences in participants and/or 
task characteristics. Whilst level of experience with the task should be comparable across studies (both studies particpants worked routinely with text at undergraduate level), it is possible that differences in task material such as font, line-spacing, content had an effect.

Whilst the findings of this study suggest that a few people grossly overestimate expected durations, a number of people underestimate as proposed by the planning fallacy. It is difficult, without a finer analysis of the data at the level of under and overestimators in the Burt and Kemp (1994) study, to ascertain exactly to what extent the findings of both studies concur or disagree.

It is interesting to note the difference in estimation accuracy between the two types of prospective tasks; the puzzle task estimates being more accurate than the video task estimates. In general, video durations were underestimated more than puzzles, in other words people felt time passed more quickly whilst watching the videos than completing the puzzles. Completing a puzzle is a more cognitively demanding task than watching a video. This finding fails to support the attentional model of time estimation (e.g. Thomas \& Weaver,1975; Maramas,1995), which would predict that the more demanding task is perceived as shorter in duration because less attention is given over to time monitoring and putting down STUs. As mentioned previously whilst this might apply for the estimation of short duration (seconds) tasks, for longer tasks (minutes) other variables such as interest level might be more relevant. The more interested one is in a task then the more attention is likely to be paid to it and the less to the timer and putting down STUs. Eighty six per cent of 
participants expressed high interest in the videos and only $44 \%$ in the puzzles. Video estimations were generally shorter. People who thought the puzzles were very interesting estimated time as passing more quickly than those who thought it boring. These results suggest that interest might be an important variable for predicting duration estimation at the level of minutes rather than seconds. (It is likely that this effect was not found for videos because of the restriction in range in the interest varaible for videos.)

The increased accuracy with the puzzles may also be because completing a crossword puzzle has temporal cues (e.g. the number completed so far, or the fact that the bulk of clues are completed in the first ten minutes, after which deeper problem-solving strategies are employed); whereas it might be generally accepted that video tapes do not contain such cues as time is often distorted (e.g. one can see a lifetime's story in one hour).

\section{Time management and time estimation}

Previous research has examined relationships between errors in expected estimates and self-report of time management behaviours through the TSQ (Burt \& Kemp 1994). The present study attempted to extend this work by incorporating prospective estimation durations and other measures of time management behaviours. Whereas Burt and Kemp (1994) found that those who scored highly on structured Routine were poorer at estimating expected durations, this study did not. When using the TMBS as the self-report 
measure, the current study did support the hypothesis that those who perceive themselves as in control of their time (Control), or as practising time management behaviours (Total Time Management) estimated expected durations more accurately than those who did not. The TSQ result (Routine) in the present study also does not support Burt and Kemp's (1994) findings; in the present study those high in Routine were better at estimating duration. Interestingly, signed analyses showed that people who both over and underestimate expected durations perceive themselves as equally poor at time management, it is the accurates who perceive themselves as good at time estimation.

As far as time in passing (prospective) estimates are concerned, participants who perceive themselves to be good at setting goals and priorities (Goalsetting), good at planning and scheduling (Planning) and to have a structured routine (Routine) are shown to be poor at estimating time-in-passing. Examination of the signed analyses reveal interesting differences between groups. Underestimators perceive themselves as good at time management. Whilst carrying out a task they estimate time as passing more quickly than it actually does. This might be explained from an attentional model perspective by proposing that, through an over-zealous monitoring of time and attention to the cognitive timer, they actually put down more STUs than are appropriate in the given time, experience time as flowing more rapidly and hence underestimate a target interval. This may be a motivational strategy, as suggested earlier, relating to a sense of control over time as it ensures they will always be on time for the next task. It may also reflect the fact that people who perceive themselves as good at time management depend very 
heavily on the external cues of a watch to monitor time-in-passing, and this underestimation is a cautious reaction to its removal. Being early or on time does not have the same consequences as being late.

In summary, the findings of this study suggest that those who perceive themselves as effectively utilising time management behaviours are accurate at estimating the duration of a future task but tend to underestimate time-inpassing. Whilst the findings have been discussed in the context of existing theoretical models of time estimation, the need for further work to consider whether such models are appropriate in the time management domain and the effect of different motivation strategies on time estimation has been identified. 


\section{References}

Barling,J., Kelloway,E.K. \& Cheung,D. (1996). Time management and achievement striving interact to predict car sales performance. Journal of Applied Psychology, 81, 6, 821-826.

Block, R. A. (1978). Remembered duration: effects of event and sequence complexity. Memory and Cognition, 6, 320-326.

Block, R. A. (1989). Experiencing and remembering time:

Affordances, context and cognition. In I. Levin, \& D. Zakay (Ed.), Time and Human Cognition: A Life Span Perspective (pp. 333-363). Amsterdam: North Holland.

Bond, M. J., \& Feather, N. T. (1988). Some correlates of structure and purpose in the use of time. Journal of Personality and Social Psychology, 55 (2), 321-329.

Buehler,R., Griffin,D., \& Ross,M. (1994). Exploring the "Planning Fallacy": Why people underestimate their task completion times. Journal of Personality and Social Psychology, 67, 3, 366-381.

Burt, C. D. B., \& Kemp, S. (1994). Construction of activity duration and time management potential. Applied Cognitive Psychology, 8, 155-168. 
Burt, C.D.B., \& Popple,J.S. (1996). Effects of implied action speed on estimation of event duration. Applied Cognitive Psychology, 10, 53-63.

Britton,B.K., \& Tesser,A. (1991). Effects of time management practices on college grades. Journal of Educational Psychology, 83, 405-410.

Francis-Smythe, J. A. and Robertson, I. T. (under review). Time related individual difference constructs. (Manuscript available from the first author).

Glicksohn, J. (1996). Entering trait and context into a cognitivetimer model for time estimation. Journal of Environmental Psychology, 16, 361-370.

James,W. (1890). The principles of psychology (Vol.1). New York: Henry Holt \& Co.

Kahneman,D., \& Tversky,A. (1979). Intuitive prediction: Biases and corrective procedures. TIMS Studies in Management Science, 12, 313-327.

Lakein, A. (1973). How to get control of your time and your life. New York: The New American Library. 
Landy, F. J., Rastegary, H., Thayer, J., \& Colvin, C. (1991). Time urgency: the construct and its measurement. Journal of Applied Psychology, 76(5), 644-657.

Lim,Y.M. (1993). Time dimensions of work: relationships with perceived organisational performance. Journal of Business and Psychology, 8, 91-102.

Macan, H. T., Shahani, C., Dipboye, R. L., \& Phillips, A. P. (1990).

College students' time management:correlations with academic performance and stress. Journal of Educational Psychology, 82, 760-768.

Marmaras,N., Vassilakis,P. \& Dounias,G. (1995). Factors affecting accuracy of producing time intervals. Perceptual and Motor Skills, 80, 1043-1056.

Murrack,P.E. (1997). The structure of perceptions of time. Educational and Psychological Measurement, 57, 2, 222-240.

Ornstein, R. E. (1969). On the experience of time. Middlesex, England: Penguin Books.

Predebon,J. (1996). The relationship between the number of presented stimuli and prospective duration estimates:The effect of 
concurrent task activity. Psychonomic Bulletin and Review, 3,(3), 376-379.

Pedri, S., \& Hesketh, B. (1993). Time perception: Effects of task speed and delay. Perceptual and Motor Skills, 76, 599-608.

Rammsayer,T.H. (1997). On the relationship between personality and time estimation. Personality and Individual Differences, 23, 5, 739-744.

Shahani, C., Weiner, R., \& Streit, M. K. (1993). An investigation of the dispositional nature of the time management construct. Anxiety, Stress and Coping, 6, 231-243.

Thomas, E. A. C., \& Weaver, W. B. (1975). Cognitive processing and time perception. Perception and Psychophysics, 17, 363-367.

Usunier, J. G., \& Valette-Florence, P. (1994). Perceptual time patterns. Time and Society, 3 (2), 219-241. 
Table 1

A typology of time estimation studies

\begin{tabular}{|c|c|c|c|c|}
\hline Study & $\begin{array}{l}\text { Theoretical } \\
\text { model }\end{array}$ & Paradigm & Method & $\begin{array}{l}\text { Duration } \\
\text { interval } \\
\end{array}$ \\
\hline Buehler et al. (1994) & $\begin{array}{l}\text { Attribution } \\
\text { theory }\end{array}$ & Expected & Verbal estimate & Days \\
\hline Burt et al.(1994) & $\begin{array}{l}\text { Event } \\
\text { reconstruction }\end{array}$ & Expected & Verbal estimate & Minutes \\
\hline $\begin{array}{r}\text { Predebon (1996) (a) } \\
\text { (b) }\end{array}$ & $\begin{array}{l}\text { Attentional } \\
\text { models } \\
\text { Attentional } \\
\text { models }\end{array}$ & Retrospective & $\begin{array}{l}\text { Graphical } \\
\text { estimate } \\
\text { Reproduction }\end{array}$ & $\begin{array}{l}\text { Seconds } \\
\text { Seconds }\end{array}$ \\
\hline Rammsayer (1996) & ? & Retrospective & Reproduction & Seconds \\
\hline Burt et al.(1994) & $\begin{array}{l}\text { Event } \\
\text { reconstruction }\end{array}$ & Retrospective & Verbal estimate & Minutes \\
\hline Marmaras (1995) & $\begin{array}{l}\text { Attentional } \\
\text { models }\end{array}$ & Prospective & Production & Seconds \\
\hline Glicksohn (1996) & $\begin{array}{l}\text { Attentional } \\
\text { models }\end{array}$ & Prospective & Production & Seconds \\
\hline
\end{tabular}


Table 2

$\underline{\text { Mean duration estimates in seconds for each task }}$

\begin{tabular}{llll}
\hline Task & N & Mean & SD \\
\hline Actual & 47 & 357 & 132 \\
Expected & 47 & 429 & 437 \\
Retro & 47 & 409 & 227 \\
Prospective & & & \\
Video* (mean) & 46 & 488 & 134 \\
Prospective & & & \\
Puzzle* (mean) & 44 & 583 & 126 \\
Video 1* & 46 & 475 & 136 \\
Video 2* & 45 & 486 & 182 \\
Puzzle 1* & 44 & 592 & 128 \\
Puzzle 2* & 43 & 569 & 170 \\
\hline
\end{tabular}

* Target $=600$ secs. 
Table 3

Medians and inter-quartile deviations of expected, actual and retrospective duration estimates

\begin{tabular}{|c|c|c|c|c|c|c|}
\hline Task & $\begin{array}{l}\text { Expected } \\
\text { median }\end{array}$ & $\begin{array}{l}\text { Inter- } \\
\text { quartile } \\
\text { deviatio } \\
\mathrm{n}\end{array}$ & $\begin{array}{l}\text { Actual } \\
\text { median }\end{array}$ & $\begin{array}{l}\text { Inter- } \\
\text { quartile } \\
\text { deviatio } \\
\text { n }\end{array}$ & $\begin{array}{l}\text { Retrospec } \\
\text {-tive } \\
\text { median }\end{array}$ & $\begin{array}{l}\text { Inter- } \\
\text { quartile } \\
\text { deviatio } \\
\mathrm{n}\end{array}$ \\
\hline $\begin{array}{l}\text { Spell-check } \\
\text { (this study) }\end{array}$ & 300 & 293 & 349 & 154 & 360 & 245 \\
\hline $\begin{array}{l}\text { Proof-read } \\
\text { (Burt et al., } \\
\text { 1994) }\end{array}$ & 900 & 300 & 660 & 330 & 690 & 272 \\
\hline
\end{tabular}


Table 4

Means, standard deviations of the proportional error estimates

\begin{tabular}{|c|c|c|c|c|c|c|c|c|c|c|c|c|}
\hline & \multicolumn{3}{|c|}{ Non-signed } & \multicolumn{3}{|c|}{ Signed } & & & & & & \\
\hline & & & & \multicolumn{3}{|c|}{ Overs } & \multicolumn{3}{|c|}{ Accurates } & \multicolumn{3}{|c|}{ Unders } \\
\hline & $\mathrm{N}$ & Mean & $\mathrm{SD}$ & $\mathrm{N}$ & Mean & SD & $\mathrm{N}$ & Mean & SD & $\mathrm{N}$ & Mean & SD \\
\hline Expected & 48 & 0.51 & 0.50 & 13 & 1.10 & 0.67 & 12 & 0.01 & 0.12 & 23 & -0.40 & 0.09 \\
\hline Retrospective & 48 & 0.29 & 0.29 & 17 & 0.52 & 0.34 & 22 & -0.03 & 0.10 & 9 & -0.37 & 0.13 \\
\hline $\begin{array}{l}\text { Prospective } \\
\text { (video mean) }\end{array}$ & 47 & 0.23 & 0.16 & 11 & 0.11 & 0.16 & 18 & -0.14 & 0.04 & 18 & -0.41 & 0.06 \\
\hline $\begin{array}{l}\text { Prospective } \\
\text { (puzzle mean) }\end{array}$ & 47 & 0.15 & 0.11 & 14 & 0.22 & 0.12 & 16 & -0.01 & 0.06 & 17 & -0.24 & 0.11 \\
\hline
\end{tabular}


Table 5

$\underline{\text { Signed error ranges of overestimators, accurates and underestimators }}$ within each paradigm

Overestimators

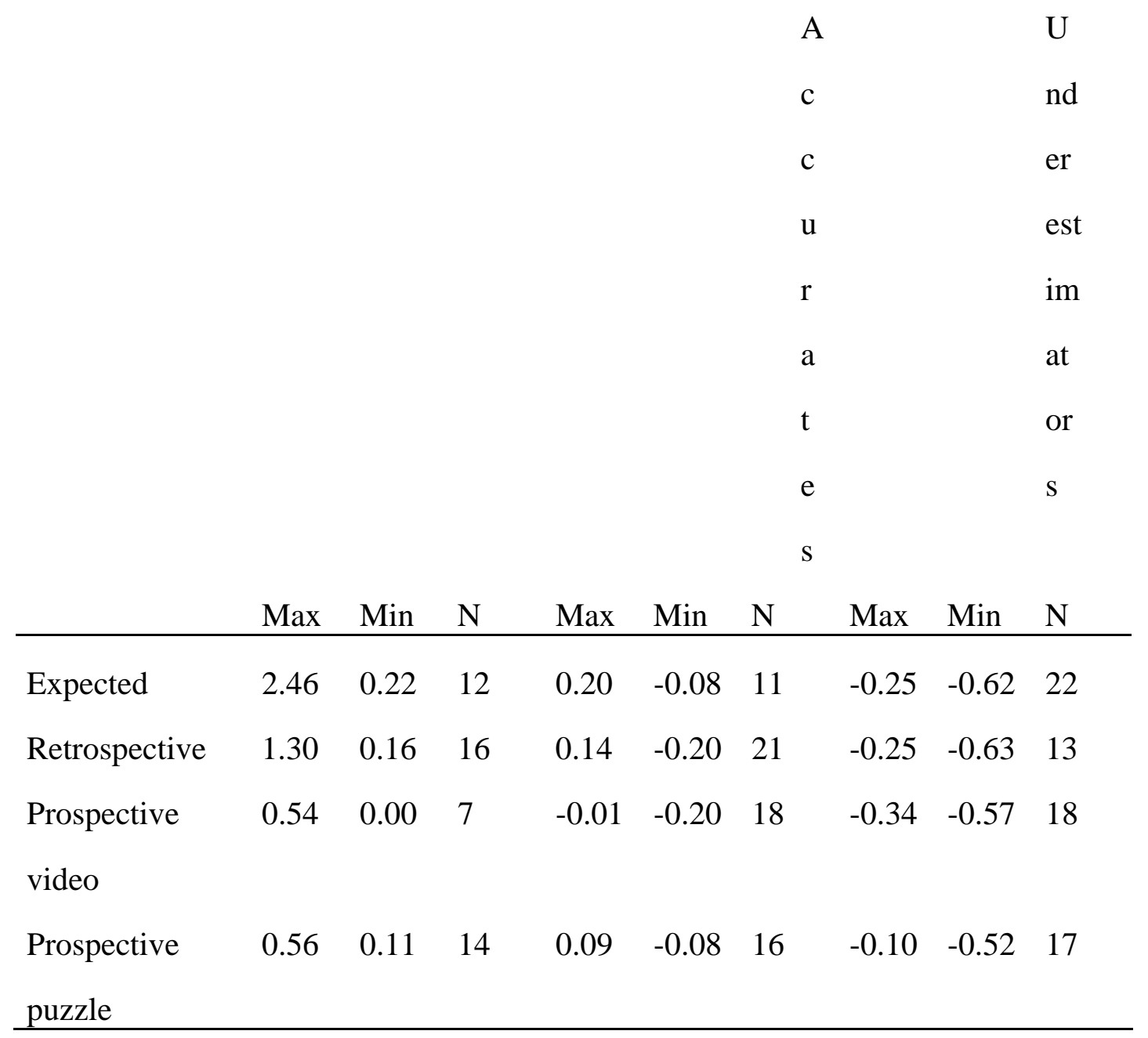


Time Management and Time Estimation 
Table 6

$\underline{\text { Pearson correlations between non-signed proportional error scores }}$ and self-report measures

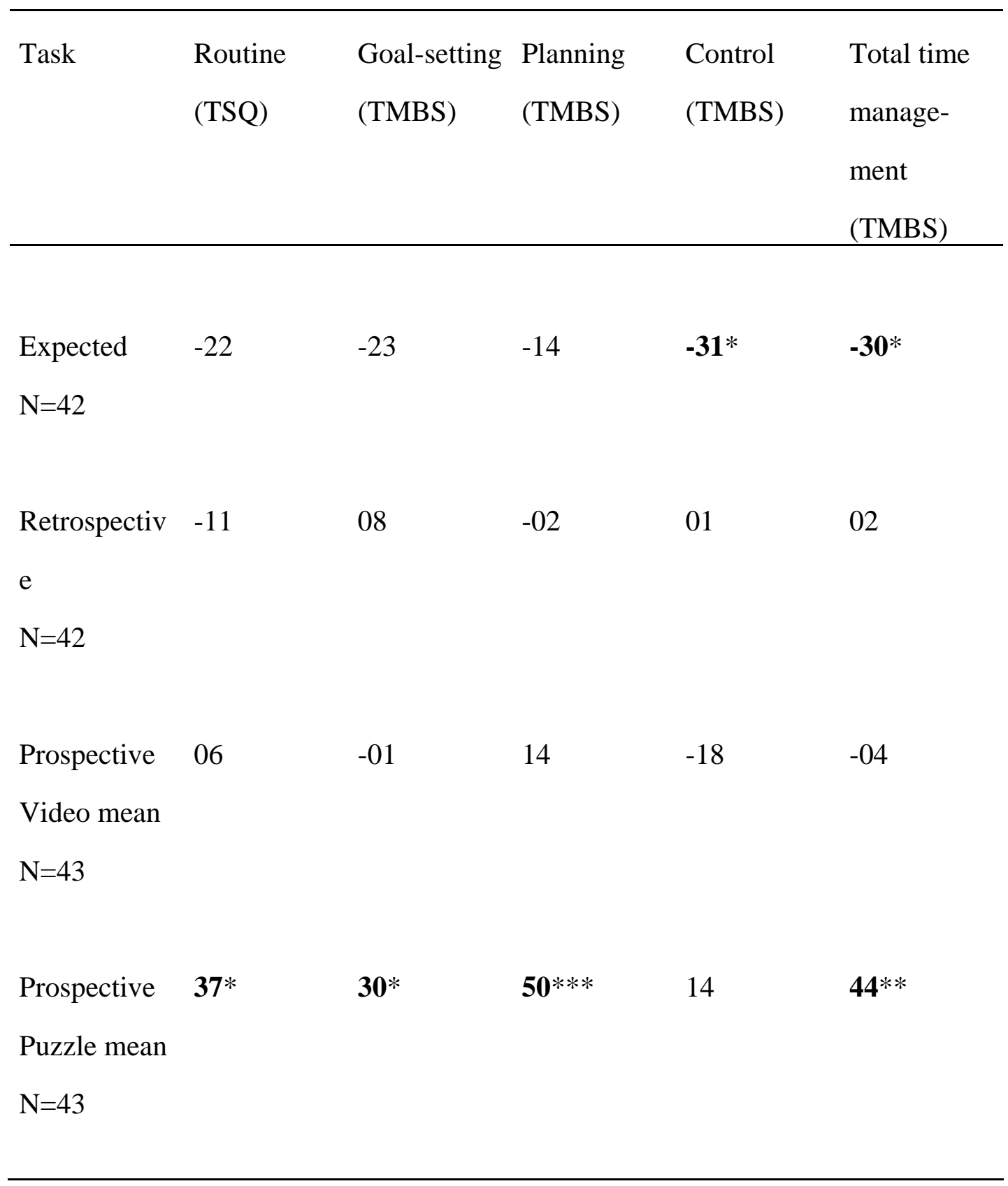

${ }^{*} \mathrm{p} \prec 0.05 ;{ }^{* *} \mathrm{p} \prec 0.01 ;{ }^{* * *} \mathrm{p} \prec 0.001$ 
Table 7

Means of self-report time management variables for over-estimators, accurates and under-estimators in each of the expected,retrospective and prospective tasks

\begin{tabular}{|c|c|c|c|}
\hline & Over-estimators & Accurates & Under-estimators \\
\hline \multicolumn{4}{|l|}{ Expected } \\
\hline Routine & 18 & 21 & 20 \\
\hline Goal-setting & 46 & 48 & 46 \\
\hline Planning & 35 & 38 & 35 \\
\hline Control & $40 * * *$ & $48 * * *$ & $40^{* * *}$ \\
\hline TotalTM & 136 & 149 & 138 \\
\hline \multicolumn{4}{|c|}{ Retrospective } \\
\hline Routine & 19 & 21 & 20 \\
\hline Goal-setting & 46 & 47 & 48 \\
\hline Planning & 36 & 35 & 38 \\
\hline Control & 43 & 43 & 39 \\
\hline TotalTM & 138 & 140 & 143 \\
\hline \multicolumn{4}{|l|}{ ProsVideo } \\
\hline Routine & 19 & 21 & 21 \\
\hline Goal-setting & 45 & 47 & 47 \\
\hline Planning & 38 & 32 & 39 \\
\hline Control & 45 & 42 & 41 \\
\hline TotalTM & 144 & 137 & 143 \\
\hline \multicolumn{4}{|l|}{ Pros Puzzle } \\
\hline Routine & 19 & 18 & 22 \\
\hline Goal-setting & 47 & 45 & 49 \\
\hline Planning & $34 *$ & $33 *$ & $41^{*}$ \\
\hline Control & 43 & 42 & 42 \\
\hline
\end{tabular}


Time Management and Time Estimation

TotalTM

140

136

146

$\mathrm{p}<0.05 ; \mathrm{p}<0.001$ 
Time Management and Time Estimation 